Swarthmore College

Works

6-1-2018

\title{
What Will Be Best For Me? Big Decisions And The Problem Of Inter-World Comparisons
}

Peter Baumann

Swarthmore College, pbauman1@swarthmore.edu

Follow this and additional works at: https://works.swarthmore.edu/fac-philosophy

Part of the Philosophy Commons

Let us know how access to these works benefits you

\section{Recommended Citation}

Peter Baumann. (2018). "What Will Be Best For Me? Big Decisions And The Problem Of Inter-World Comparisons". Dialectica. Volume 72, Issue 2. 253-273. DOI: 10.1111/1746-8361.12219

https://works.swarthmore.edu/fac-philosophy/566

This work is brought to you for free by Swarthmore College Libraries' Works. It has been accepted for inclusion in Philosophy Faculty Works by an authorized administrator of Works. For more information, please contact myworks@swarthmore.edu. 


\title{
What Will Be Best for Me? Big Decisions and the Problem of Inter-World Comparisons
}

\author{
Peter Baumann \\ published in: \\ Dialectica 72.2, 2018, 253-273 \\ The definitive version is available at wileyonlinelibrary.com - \\ https://onlinelibrary.wiley.com/doi/10.1111/1746-8361.12219
}

\begin{abstract}
Big decisions in a person's life often affect the preferences and standards of a good life which that person's future self will develop after implementing her decision. This paper argues that in such cases the person might lack any reasons to choose one way rather than the other. Neither preference-based views nor happiness-based views of justified choice offer sufficient help here. The available options are not comparable in the relevant sense and there is no rational choice to make. Thus, ironically, in many of a person's most important decisions the idea of that person's good seems to have no application.
\end{abstract}

KeYwords: Adaptive Preferences; Big Decisions; Future Selves; Good of a Person; Happiness; Incomparability; Rational Choice.

Simone is facing a big decision: to have a child (soon) or to remain childless (at least for the time being, if not forever). She knows that if she decides to have a child, then she will have one in all probability (whether as the child's biological mother or by adoption, etc.); she also knows that if she decides not to have a child, then she will not have one in all probability. ${ }^{1}$ To have one or not to have one are her only options, and she knows that. She must decide now (though not within

1 If she decides one way or the other, she will stick with her decision. 
the next 30 seconds, of course). What should guide her deliberation and choice? What should she do $?^{2}$

It is very plausible though not overly informative to say that Simone should do what is best. ${ }^{3}$

What does this mean? If one of the two choices is better than the other, then she should choose

the better one. If they are equally good, then she may choose either option. ${ }^{4}$ What determines

being good, better or best? Let us assume that there are no moral or ethical issues to consider in

Simone's case. ${ }^{5}$ The question is what is good, better or best for her. There are several different

interpretations of "what is good for someone". I will focus on two main interpretations: on what

satisfies the person's preferences or on what makes her happy. ${ }^{6}$ These notions admit themselves

2 It seems that often having children is not based on prior decisions and even if it is based on prior decisions those decisions are often not or at least not to a large degree based on rational deliberation. However, this is besides our topic which concerns the possibility of making rational choices in such cases. - For a similar type of case see, e.g., Gibbard 1986, 176-177. For the notion of a big decision see, e.g., Ullmann-Margalit 2006 , sec.II. We can follow her in assuming that big decisions are transformative of the person and hard (if at all) to revoke.

3 One could argue for something weaker, like: she should try to do what seems best to her. I won't argue for the strong version above. Nothing in what follows depends on choosing the strong version.

4 Doesn't that mean that in such a case Simone may flip a coin and pick rather than choose (see UllmannMargalit \& Morgenbesser 1977 on this important distinction)? Doesn't this seem problematic? This strategy seems adequate when facing a relatively trivial choice: if almond ice-cream is equally good for me as cucumber ice-cream, and if I have to choose, then I might as well flip a coin. However, it is not clear that this style of decision-making is without problems when an important, big decision is concerned (whatever the criteria for triviality or big-ness). Perhaps we have reasons to defer the decision when there is a tie in big decisions (a "big tie") and hope that as time goes by the tie will turn out to have been merely apparent. The costs of deferral might be small compared with the risk of making the wrong choice and having to face the consequences. Even if there is no big tie but a small difference between the options in a big decision many people would be reluctant to just choose the slightly better option. I won't discuss the question here whether such reluctance is rational and justified or not.

5 If the reader has doubts whether one can ignore such aspects, they could easily change the example to a less contentious one. An example involving a choice between very different career options, for instance, would work as well. - If one holds that all choices have a moral aspect, then one should abstract away from it in the current discussion. Abstracting away from certain features of reality is a normal and often legitimate way of doing inquiry.- It is certainly true that whatever we choose and do will create new moral issues, and different ones depending on our choice: if I choose to spend next Sunday gambling in a casino I will probably encounter (along the way) different moral issues than if I choose to spend next Sunday participating in a neighborhood street party. This, however, does not mean or entail that the initial choice itself is or has to be a moral choice or a choice with non-negligible moral dimensions.

6 Often preference satisfaction is also counted as a type of happiness. That we go with a narrower concept of happiness doesn't matter to the argument. - I am leaving aside here views according to which what is good 
of more than one explanation but we need not deal with these details here. Using the language of

orthodox rational choice theory, we could also say that one should maximize one's expected

utility or, given that we can disregard probabilities in our case, that one should go for the greater

or greatest utility. And utility has traditionally either been interpreted as happiness or as

preference satisfaction $(\mathrm{xxx}$.

I will argue that cases like Simone's constitute a modal analogue (limited, of course, in certain ways) to the well-known problem of interpersonal comparison of utility. ${ }^{7}$ In contrast to other authors $^{8}$ I will argue for a skeptical view: namely, that in cases like Simone's there is no good

for a person is determined by an "objective list" (see, e.g., Hurka 1993 or Wolf 1997). I take it that plausible objective list theories also have to be agent-relative in the sense that for sufficiently different people the objective list entails different specific verdicts about the good. Problems analogous to the ones presented below also arise then for plausible objective list theories. Objective list theories which are not agent-relative might or might not be defensible but they don't seem relevant to the personal big decisions under discussion here. If someone wanted to argue that having a child is objectively good for everyone, then we could easily find a different example where it is incorrect to say that the same thing is good for everyone.

7 See, e.g., Robbins 1938, Neurath 1973, Schlick 1939, 88-89, Little 2002, ch.IV, Arrow 1963, 9, Harsanyi 1977a, Harsanyi 1977b, 51-60, Sen 1970, Hare 1981, ch.7, Griffin 1986, ch.VII, Adler 2012 ch.3 (see 225 227 briefly on inter-world comparisons). For overviews see, e.g., Elster and Roemer 1991, Hammond 1991, Harsanyi 2008, Binmore 2009 as well as Drakopoulos 1989 and Hennipman 1995 for historical overviews. - This paper can be seen as arguing that problems somewhat analoguous to ones arising for interpersonal comparisons of utility arise for intrapersonal "inter-world" comparisons of the utilities of different possible future selves of the same person. However, I am not using claims about the possibility or impossibility of interpersonal comparisons of utility as support for my argument to the effect that there are deep problems with intrapersonal and inter-world comparisons of utility. The arguments for the latter can and should stand on their own. Perhaps, there is rather a connection in the other direction: the doubts presented here concerning the possibility of intrapersonal and inter-world comparisons of utility might also indirectly strengthen the case of the skeptic about interpersonal comparisons of utility. However, given the topic of this paper, I can remain agnostic about the possibility or impossibility of interpersonal comparisons of utility here. The two kinds of comparisons are different enough, despite all the analogies. - Problems concerning intertemporal and intrapersonal comparisons of utility (see, e.g., Broome 1991) are sufficiently different from the ones discussed in this paper. In those cases we try to compare and balance the utilities of an earlier and a later actual self whereas in our case we are dealing with the comparison and balance between the utilities of two different future possible selves, not including the actual present self. We can thus put problems of intertemporal and intrapersonal comparisons aside here. For the case of intertemporal one-person comparison of utilities see Schoeffler 1952 who is skeptical about that possibility.

8 See, e.g., Bricker 1980, 393-398 or, more recently, Bykvist 2010a and Bykvist 2010b. Both authors propose a solution discussed below. They both presuppose rather than argue for the possibility of making the kind of utility comparisons between different persons or possible selves that I am discussing here. See also the brief remarks in Gibbard 1986, 176-177. 
answer to the question what she ought to do. The basic reason for this has to do, as we will see, with rather implicit parameters of utility determinations (and comparisons) which can vary between different possible future selves. Utility understood as preference satisfaction is relative to ranges of options while utility understood as happiness is relative to bounds of experience, degrees of sophistication and normative standards. These implicit relativities haven been neglected in discussions so far. Classical theories of rational choice seem to give us hope that in principle there is always an answer to the question what one ought to do in a particular situation, including when one has to make big decisions. The conclusion of this paper runs against this and suggests, rather, that especially in the case of big decision there often simply is no better or best option.

\section{Possible Future Preferences}

(a) Satisfying Future Preferences

Let us consider the idea of preference satisfaction ${ }^{9}$ first: the idea that Simone should choose according to her preferences. This is not yet specific enough. That she should decide according to her preferences does not mean that she should decide according to her current preferences about the options. People's preferences change and we can assume that Simone knows this. Which preferences are relevant then for her decision: her current or her (expected) future ones (or even her past ones?)?

9 "Preferences" should be taken in a wide sense here, also covering, for instance, pro-attitudes based on wellreflected life plans. The term should certainly not be taken as only covering whims of the moment or similar attitudes. If there are worries about the acceptability of unreflected whims, then we may just assume that Simone's preferences are as well reflected as can be expected. We also do not have to worry about the case of defective preferences (false desires or irrational and unenlightened preferences). The problem discussed here arises no matter whether we restrict our discussion to preferences qualified in one of the above ways or not. 
We can set aside the problem whether Simone can know or have good reason to believe that such and such will be her specific future preferences (we can assume that she will have some rough idea about the kinds and types of preferences she will have). Our problem is not an epistemic one. More importantly, we don't need to raise the question whether persons have good reasons to take their expected (future) preferences into account as against their present (or even: past but not present) preferences and what relative weight they should now give to those (expected) future preferences. Simone's question “What should I do?” only makes (interesting) sense if asked from the perspective of her (expected) future self with her (expected) future preferences; her question as such is posed as one concerning her future good and her future preferences (which determine her future good according to the view under consideration). Simone thinks about things on behalf of her future self. ${ }^{10}$ Were she to take the question as one about whether she prefers now (or even: preferred in the past) to be a person with a child in her future or to be a person without a child in her future, she would ask a different question, and a hardly intelligible one. To be sure, Simone might also now have second-order preferences to have certain firstorder preferences for or against having a child later. However, even if one takes the role of second-order preferences in a person's life very seriously (see Frankfurt 1971), it should be clear that our main question is not about that: the question is whether one should go for having a child or not, it is not about whether one wants to be or should want to be a person who wants to have a child or not. So, if Simone wants to do what's best for her, then she needs - according to the preference satisfaction view - to go by her (expected) future preferences. If her (expected) future self prefers having a child, then she should now choose to have one; if not, then not.

10 See also fn.13 below. - The problem is thus different from the problem of how to weigh the attitudes of the old self against those of the new self. For this see, e.g., Ullmann-Margalit 2006, 167. 
All this might seem much more straightforward than it really is. The problem is that particularly in the case of big decisions lots of things change with and after the decision, amongst them the preferences of the decision maker. As is well known, there is a two-way dependency between decisions and preferences: we make decisions on the basis of preferences but our decisions also shape and change our preferences (especially in the case of big decisions). Many people decide to have children because they want to and amongst the causal consequences of their decision are new (or strengthened) positive attitudes towards the idea of having children and towards their own children. Similarly, many people who decide not to have children will have a kind of life that strengthens or brings about attitudes incompatible with a life with children. Of course, a person's decision to X can also bring about a preference not to X. But we can focus on the former case of "self-confirming" decisions and leave the case of such "self-disconfirming" decisions aside. ${ }^{11}$ We can also assume that Simone expects her decision to be self-confirming. ${ }^{12}$

Let us thus assume that Simone faces a self-confirming choice situation. Her current set of preferences P-0 is not relevant as far as the first-order question "to have or to have not?" is concerned; as mentioned above, she is dealing with a decision on behalf of her future self. ${ }^{13}$ Let

11 There is an interesting parallel here with self-fulfilling and self-destroying predictions which might be worth exploring in another context. On self-confirming choices see also Harman 2009. Some preferences underlying self-confirming decisions are adaptive: What the person wants adapts to what she (thinks she) can get (see, e.g., Elster 1982).

12 If the subject believes that her choices will not be self-confirming though also not self-disconfirming, then the problem presented here does not arise in quite the same way (no matter whether the subject's belief is false and the choices are in fact self-confirming). For the sake of simplicity, we can thus leave these cases aside. Therefore, we can also leave the role of expected future regret aside in this paper. If the subject, however, believes that her choices will be self-disconfirming, then the same things will hold, mutatis mutandis, as for the case of self-confirming choices. For the sake of not complicating things unnecessarily, we can also leave this case aside here.

13 If you disagree, just assume that Simone is still young, hasn't thought much at all about children and does not have preferences now about having or not having children. This is not indifference in the sense of both options being equally good for her: answering the question with "Both are good" is different from not having an answer in the first place. - If one were to assume that Simone already has a view at the time and a preference for or against having a child, then things would only get more complicated without changing 
us thus make the following assumptions (realistic ones if Simone is a typical person). If she were to decide to have children, then her set of preferences would change quite a bit: from P-0 to a new set P-c where P-c is a set of preferences of someone who strongly prefers to have children over not having children and is also happy about having children. Given P-c, it would be according to the view under discussion - better for Simone to have children than to remain childless. On the other hand, were Simone to decide to remain childless, her set of preferences would change quite a bit, again, namely from P-0 to the new set P-n where P-n is a set of preferences of someone who strongly prefers not to have children over having children and is also happy about not having children. Given P-n, it would be - again, according to the view under discussion - better for Simone to remain childless than to have children. Suppose Simone knows (justifiably believes, etc.) all this. What ought she to do? Is there something she ought to do?

Simone could say that her options are both good ones - but what could that mean? It could mean that both decisions would lead to a situation where she would consider (and have good reasons to consider) the original decision to have been a good one and where she would prefer the original decision to the alternative one (which she might then even consider not to be a good one). However, for each of her two possible future selves, Simone-c and Simone-n, the preferred choice would be a different one in their respective situation. Given P-c, having a child is so much better than not having one; given P-n, not having a child is so much better than having one. Since

the problem or the arguments, given that Simone is trying to make a decision on behalf of her future self; this is an additional reason to restrict ourselves to the case where she now has no preferences of the relevant kind. - We can also leave aside past preferences: they count only if endorsed by current preferences which are irrelevant here - or by future preferences to which they would then not add anything. (I am leaving aside the possibility that in some very special cases past preferences might count even if not endorsed by current or future preferences). 
one cannot make a decision "from nowhere" but only on the basis of some set of preferences, we face a problem. P-0 doesn't help at all, P-c and P-n suggest contradicting choices and there is no other present, future or possible set of preferences that is relevant to the question and is one of Simone's possible sets of preferences. No meta-criteria (which would, for instance, tell us that Pc has, for reasons of type T, more weight than P-n) are in sight. It also won't help to say that the future (world) which is closer to the actual present (world) weighs more, - that is, the future world which is closer to the actual world up to the present. There is the well-known and notorious difficulty of coming up with a non-arbitrary closeness ranking for possible worlds (see amongst many Bowie 1979, Krasner \& Heller 1994 or Morreau 2010; for an application see Wilburn 2010). And even if we are helping ourselves to a somewhat intuitive notion of closeness (as far as Simone's choice is concerned), it seems quite plausible to say that which future world will appear closer to the actual world up to the present depends on which decision is being made; the decision for a child makes world-c and the decision against a child makes world-n seem closer to the actual present. So, closeness cannot factor into the reasons for deciding one way or another.

(b) Measuring Degrees of Satisfaction

But couldn't we compare how well Simone-n's preferences are met with how well Simone-c's preferences are met? To be sure, if we only look at their preferences concerning having or not having a child, then in our case both Simone's preferences would be met completely. But this idea won't help. Simone wants to know which preference she should satisfy; from the fact that a preference for A (which is awful) and a preference for B (which is wonderful) can both be completely met it doesn't follow that the subject may choose either. However, a closely related 
idea might seem much more interesting: couldn't we compare the degree of overall preference satisfaction in Simone-n's life with the degree of overall preference satisfaction in Simone-c's life? This would enable us to answer the question what Simone should do: she should choose the option (if any) that leads to the higher (or highest) degree of overall preference satisfaction (see, e.g., Bricker 1980, 393-398 or, more recently, Bykvist 2010a, esp. 21, who argue for this kind of view).

How could one do this? We could identify options with states of the world (types, not tokens) and take into account all options between which the person has a preference. We could proceed in the classical way (see, e.g., Ramsey 1990, xxx, or von Neumann \& Morgenstern 1953, xxx) and assign the value 0 to the option least preferred by the person, the value 1 to the option most preferred by the person, and real values between 0 and 1 to all intermediate options. Following the usual method will give us a cardinal scale (xxx), not just an ordinal one (which would be useless for our purposes). The corresponding utility function is unique up to positive linear transformation.

Our cardinal scale would enable us to measure relative strength of preferences and thus the value or utility of the satisfaction of the different preferences. We can use this idea to measure the whole life preference satisfaction. We would assign a value of $c_{w}$ to Simone-c's whole life satisfaction and a value of $\mathrm{n}_{\mathrm{w}}$ to Simone-n's whole life satisfaction. However, it is not clear at all, to say the least, how this can be done. Should we add the values of all the met preferences and subtract the values of all the unmet preferences? Should we multiply? Do we need some additional constants? It is not easy so see how such questions about the aggregation of particular 
preferences could be answered in a plausible and principled way. Apart from that, there is a problem of relevance. The degree of satisfaction of the specific preference we're interested in (for or against having a child) is only a part of the degree of overall preference satisfaction. The degree of overall preference satisfaction is determined by many different factors and certainly not only or not even to the largest part by the degree of satisfaction of the specific target preference we're interested in here (to have or not to have a child). The overall preference satisfaction depends on all of Simone's preferences on all kinds of things as well as on her decisions on all kinds of issues and the corresponding outcomes as well as on events independent from her decisions. A certain degree of overall preference satisfaction thus does not entail anything about whether it was a good idea to have a child or not. Consider A and B who both clearly prefer to have a child over not having a child. Suppose that A's other preferences are very easy to satisfy while B's other preferences are very hard to satisfy. It could then very well be that A's overall preference satisfaction is very high and B's very low. But this does not speak to the question whether they each should have a child; it rather speaks to the different question how they should decide each and every issue that comes up. So, it is not clear at all why the degree of overall preference satisfaction should be considered unconditionally relevant for the question whether Simone is better off with or without a child. This problem suggests that we might perhaps be better off with returning to the former approach of restricting ourselves to the target preference.

Both approaches have their problems and consideration of each seems to lead us back to the other one. Perhaps a third, hybrid view could be developed which combines a whole life satisfaction view with a focus on the target preference by capturing their respective advantages 
and avoiding their respective problems? This would then give us a value of $\mathrm{c}_{\mathrm{h}}$ for Simone-c and a value of $n_{h}$ for Simone-n. It remains to be seen whether and how a convincing hybrid view can be developed. As long as nothing like that is being proposed, one should remain skeptical. Alternatively, one might try to to consider subjects' preferences over complete (or almost complete) bundles of options: over all (or: most) of the different possible combinations of all (or: most) of their particular options (having a kid, remaining unmarried, buying a house in the countryside, etc.). It is not clear though whether normal human beings are able to entertain such complex attitudes (allowing us to assign a value of $c_{t}$ to Simone-c and a value of $n_{t}$ to Simone-n). The person would also have to solve serious aggregation problems (see above) one way or another.

(c) Inter-world Comparisons and the Relativity of Satisfaction to Ranges of Options Fortunately, we don't have to choose between these different options because they all face the same underlying problem: the problem of " inter-world” utility comparisons. How can one compare utilities across different possible worlds? In our case: how can one compare the strength of preferences and the degree of satisfaction of different possible persons only one of whom will be an actual person (e.g., Simone-c and Simone-n)? If we treat Simone-n and Simone-c like different persons, then our problem just looks like a version of the well-known problem of interpersonal utility-comparison (see $\mathrm{xxx}$ ); if we don't treat them as different persons but as different possible future selves of the same person, our problem is still very much analogous to the problem of interpersonal utility-comparison of utility (see Briggs 2015). For the sake of simplicity we can consider the first approach above with its restriction to the target preference; similar things hold, mutatis mutandis, for the other approaches mentioned above. 
Suppose, again, that we assign a value of $\mathrm{c}$ to Simone-c and a value of $\mathrm{n}$ to Simone-n (with these values expressing strength of preference and utility of the satisfaction of the preference). Can we simply assume inter-world comparability and claim that each number on Simone-c's scale expresses the same strength of preference and the same degree of utility as the same number on Simone-n's scale? If yes, then Simone should decide to have a child if $\mathrm{c}>\mathrm{n}$ and decide not to have a child if $c<n$ (we can leave it open here what she should do if $c=n$ ). All this is suggested by the so-called "zero-one rule" (see xxx).

To see the problems with this idea we can ease the exposition a bit and consider an analogous temporal case. Consider a person with a certain degree of preference satisfaction at some point in time. Assume that this person is later enabled to consider an additional option which she did not or could not consider before. Suppose this additional option is preferred by the person to her former best option. This would (assuming her additional preference has not been satisfied yet) lower the degree of preference satisfaction for the person. But how could adding a new best option make a person worse off (see, e.g., Briggs 2015, sec.2 but also Hausman 1995, 482; see also Sen 1987, 46 and Jeffrey 1974, 42-43)? Or consider the case in which the formerly best option drops out of consideration by the person (for whatever reason). This would raise any formerly non-maximal degree of preference satisfaction. But how could such a narrowing of one's horizon of options make one better off? Similar points can be made about new worst options as well as about the dropping out of consideration of formerly worst options. 
Whatever we think about such changes, they strongly suggest that degree of preference satisfaction has to be relativized in an important sense: it is relative to a given (and variable) range of options. Suppose our person first enjoyed a degree of preference satisfaction of .78 and later, after a change in the range of options, one of .58. All we can say then is that the person had a degree of preference satisfaction of .78 relative to the earlier range of options and a degree of .58 relative to the later one. But it doesn't make much sense to attribute non-relativized degrees or even compare them (and, e.g., claim that some non-relativized degree of satisfaction decreased).

The same holds, mutatis mutandis, for our modal case. Given that different possible future selves of the same person - like different persons - typically have different ranges of options (it is hard to imagine how this couldn't be the case), a comparison of their respective degrees of preference satisfaction and their degrees of utility seems impossible. One can say that Simone-n has a degree of preference satisfaction of $n$ with respect to her range of options and Simone-c has one of $\mathrm{c}$ with respect to her range of options. But even if $\mathrm{c} \neq \mathrm{n}$ it still doesn’t make much sense at all to say that one of them has a higher (non-relativized) degree of preference satisfaction. And even if $\mathrm{c}=\mathrm{n}$, it still doesn't make much sense at all to say that they both enjoy the same degree of preference satisfaction. This would be like saying that Jill is a better athlete than Jo just because Jill came in second in the high-jump competition while Jo came in third in the marathon competition (also see MacKay 1975 or 1980, 61-77 for this kind of case).

Because of the relativity of strength of preference and degree of utility to given ranges of options the inter-world comparisons of utility or preference satisfaction is impossible in all realistic 
cases. At least comparisons of the kind we have discussed here (using cardinal scales unique up to positive linear transformation) are out of the question. I have discussed the issue in terms of a comparison of utility levels but the same points hold, mutatis mutandis, if we consider the idea of comparing utility differences: the difference in satisfaction as Simone turns into Simone-c as contrasted with the difference in satisfaction as Simone turns into Simone-n. The consideration of utility differences might complicate things further insofar as Simone as she is facing her options and the big decision would count as a third possible (and actual) self, sufficiently different from the other two.

\section{(d) Conclusion}

To be sure, there are other things we can still say. We can compare a person whose most important preferences have been thwarted with a person whose most important preferences have been satisfied. With respect to the respective preferences the first person might find herself below her indifference point while the second person might find herself above her indifference point (with the indifference point being determined by the value of an option the realization or non-realization of which the person is indifferent about). However, this won't help us in cases like Simone's where we are assuming that both choices will lead to an outcome considered good by the future self. One might perhaps hope to rescue the possibility of a rough and imprecise comparison of preference satisfaction between different subjects. However, since the proof of the pudding is in the eating one would have to show how this idea of rough comparison can be made to work. Apart from that, many cases - like our case of Simone - require more information than just the rough and imprecise one expressed by words like "pretty good", "kind of ok", etc. 
Big decisions of the kind Simone is facing are very common. In the light of the above remarks we have to conclude that in such cases there simply is no basis for a decision if that decision is supposed to be based in a rational way on relevant preferences of the decision maker (including her possible future selves). The idea of what is good for the person seems to be inapplicable here (see Hausman 1995, 482-486, see also Paul 2015b, 508 in reply to Briggs 2015). ${ }^{14}$ In that sense, there isn't really a choice situation then. Perhaps that is what existentialists like Sartre had in mind (see Sartre 1970 and also Ullmann-Margalit 2006, 171-172)? Eligo quia absurdum?

\section{Happiness between Worlds}

\section{(a) Comparing Happy Future Selves}

What about the other main idea here - that Simone should do what makes her happy or happiest ${ }^{15}$ (go with the greater or greatest utility in that sense)? Wouldn't this help and constitute a good idea anyway? We may assume that both decisions would lead to a happy life (and Simone knows this also or partly because she knows about the self-confirming character of her choice). But perhaps in one of the two possible future lives there will be more happiness than in the other? Then, it seems, she should choose the happier future (see Bykvist 2010b). If there wouldn't be a such a difference in happiness, then we would have a situation of indifference which would also not be a problem (but see above for some reservations): Simone would have a

14 Again: one could still say that a person in Simone's situation can make a decision that will be considered good by her future self, no matter how she decides. However, this is small consolation because we have a stronger notion of the good of a person in mind: a notion of what is good for her without further qualification.

15 - where being happy entails being in some positive (enough) state (positive for the subject). We don't need a more specific notion of happiness here. Subjective forms of hedonism should be included as well as more objective ones. For a defense of interpersonal comparability of pleasures and pains on ratio scales see Klocksiem 2008. See xxx. 
reason to choose any one of the two equally good options even if she lacks specific reasons to prefer one over the other.

All this presupposes that we can compare the happiness (its quantity and quality) in the lives of very different possible future selves. However, if the world in which Simone becomes a mother is - at least as far as Simone's situation and her psychology are concerned - very dissimilar from the world in which she remains childless, then it is very hard to see what a cross-world happiness comparison like the one needed here could look like and how it could be made. Interpersonal or inter-world comparison of utility in the sense of preference satisfaction is already tricky enough (see above). Why should we think that inter-world happiness measurement is any easier? Even if we don't take seriously the hopeless idea that both possible future Simones would experience some definite amounts of the same stuff - utils, happiness atoms or molecules, etc. -, we would still have to assume that one could meaningfully say, e.g., that Simone-c is happier than Simonen. To be sure, other comparisons are still possible, even in big decisions: for instance, when one decision would be self-disconfirming and the other one self-confirming. Joining the Légion étrangère now would make me quite miserable while continuing my civil life would be fine. ${ }^{16}$ But some life-changing choices seem to be like Simone's, with both possible decisions being self-confirming ones. And then we do have a problem with comparative judgments about happiness. It doesn't make a difference in this respect whether we consider Simone's specific happiness about having or not having a child or her happiness about her life overall (or a combination of both).

16 Rough and imprecise comparisons between persons or different possible selves might, perhaps, be possible but this won't help much here where we might need more fine-grained comparisons. 
One might try to argue that happiness supervenes on physical states. More precisely, one might try to argue that the degree of happiness supervenes on certain types of physical states of the person (including or not including her environment). Hence, on the basis of determining the relevant physical state one could in principle figure out the corresponding degree of happiness (see, e.g., Brandt 1979, 265 for a similar idea). This kind of idea is certainly controversial in principle (remember the discussion about qualia!). One problem in our context has to do with the criteria of relevance of the corresponding physical state: doesn't what physical states are relevant depend on facts about the happiness of the person (see Bergström 1982, 301-302, 305-306, and also Bradley 2008, 89 for a similar point in a slightly different context)? But even if there is a non-circular relation between physical states and happiness, this whole idea is useless for our question what Simone should do. An answer to this question would, according to this proposed procedure, require a kind and amount of knowledge which seems far out of reach (at least currently) for mere mortals like us: knowledge about the correlation between degrees of happiness and kinds of physical states. We can't (at least for the time being) proceed this way but we also don't need to: we are still able to answer some of our questions about what would make us happy in a more direct way (if we can answer such questions at all).

\section{(b) Relativity to Bounds}

There are other, more important, worries about the idea of happiness comparisons between different persons or different possible future selves; some of these worries are somewhat analogous to the ones raised above about comparisons of preference satisfaction. Persons can be more or less happy. Let us assume in addition that a person's ability to be happy or unhappy has both an upper and a lower bound; whatever one thinks about this assumption, without it would 
be hard to measure or compare the happiness of different subjects or selves, and therefore we should make it here (for measurement of happiness see, amongst many, Kahneman, Wakker and Sarin 1997). It seems plausible then also to assume that both the minimum and the maximum can vary over time for a person. In a state of severe sleep deprivation the range of possible happiness or unhappiness might well be much smaller than in a state of alertness and well-restedness. Or the appearance of new options better than all the others feasible before can extend the upper bound. Can different persons (different possible future selves) differ similarly in their respective scopes of their abilities to be more or less happy? It is hard to see how not. It seems very plausible to assume that two persons or two different possible future selves can have different sensitivities to the scope of happiness and unhappiness (also see Robbins 1938; Harsanyi 195354, 206, fn.1 but also Harsanyi 1955, 317; Sen 1987, 45; Griffin 1986, 120; Bergström 1982, 297-300; for a similar point applied to a different context see Bradley 2008, 96). But how could one then compare such different subjects' or selves' states of happiness?

What if, for instance, Simone-n shares with Simone-c the same lower bound of happiness but Simone-n is able to feel or be in states of higher degrees of happiness than Simone-c? Suppose some event E would get Simone-c pretty close to her upper bound but would get Simone-n not that close to her upper bound. Does this mean that E would make Simone-c happier than Simone-n? This claim seems unacceptable. Similar things hold for differences in lower bounds between Simone-c and Simone-n. We have to conclude that happiness is relative to given bounds. All we could say then is that Simone-c is happier relative to her bounds than Simone-n is relative to hers; we could, however, not meaningfully say that Simone is happier than Simone-n in a non-relativized sense. The relativity of happiness to bounds thus stands in the way of inter- 
world comparisons of happiness in cases like Simone's (and also of typical interpersonal comparisons of happiness). Sure, one can compare an unhappy person or self with a happy one and figure out that one is happier than the other. But here we need (see above) more fine-grained distinctions between subjects each of which is happy in a broader sense.

(c) Relativity to Degrees of Sophistication

Related to this worry is another one (see also Sen 1970, 93-94 in a different context). Suppose a person develops from being quite unsophisticated to being quite sophisticated in the following way. First she is only able to distinguish between and thus be in states of happiness of 5 different degrees (very bad, bad, ok, good, super; I am leaving aside issues of vagueness). Then she develops the ability to distinguish between and thus be in states of happiness of 15 different degrees (unbearable, miserable, ... not so bad, fine ... great, blissful). We can either consider this to be an extension of scope in which case we're back to the problem above. Or we can consider this to be an increase in fine-grainedness of the range between the most unhappy and the most happy state with the scope of upper and lower bounds remaining fixed. This would be an increase not in scope but in sophistication (it is very plausible to assume that no human subject's experiences are infinitely fine-grained; they are rather discrete than continuous). The person becomes more sensitive to the finer differences in quality of life. Does it make sense to say that different persons or different possible future selves are sophisticated to different degrees? It is hard to see how not. It is very plausible to assume that different persons or selves might indeed differ in degree of sophistication. But how then would comparison of degrees of happiness possible? 
Suppose that Simone-c would develop more sophistication and fine-grainedness of the happiness-range than Simone-n. For reasons parallel to the ones above concerning different bounds of happiness it seems dubious to assume that there is a unique, non-arbitrary correlation between degrees of happiness in Simone-c's life and degrees of happiness in Simone-n's life such that this correlation would enable us to equate certain degrees of happiness of Simone-n with certain degrees of happiness of Simone-c. Happiness also appears to be relative to type and degree of sophistication. One measuring rod might indicate meters and centimeters, another one might indicate feet and inches. Both measure the same independent property and are intertranslatable. Nothing like that exists in the case of happiness (even if we can distinguish roughly between happy and unhappy subjects).

(d) Relativity to Standards

Finally, one very crucial reason why one should be very skeptical about the possibility of comparative judgments about the happiness of two quite different possible future selves like Simone's is that judgments about happiness have an evaluative aspect (see also Scanlon 1991). Even if it is not so clear whether being a dissatisfied Socrates is better than being a satisfied pig (whatever that might mean), it is very plausible that happiness does have a qualitative aspect apart from any quantitative aspect it might have (see the classic passages in Mill, Utilitarianism, ch.II). ${ }^{17}$ There is an implicit reference to standards of the good life in comparative judgments about happiness (and in non-comparative ones, too). Given that there is a plurality of mutually

17 It is very problematic to assume that one can compare amounts of happiness of different qualitative types. It doesn't seem to make much sense at all to make claims of the following kind: A experiences a little of the high quality happiness-type $\mathrm{H}^{*}$ while $\mathrm{B}$ experiences a lot of the low quality happiness-type $\mathrm{H}$ - such that A's overall "happiness level" equals or is different from the one of B. This in itself seems to constitute a problem for the comparability of different states of happiness. I will not go further into this here. 
incompatible but equally legitimate standards of the good life ${ }^{18}$, one attributor may correctly judge that A is happier than B (given one standard of the good life) while another attributor may correctly judge that B is happier than A (given another standard of the good life). ${ }^{19}$ Many people would, for instance, have judged that Wittgenstein had a pretty unhappy life, often bordering on suicide, while Wittgenstein himself is said to have judged at the end of his life that he had had a "wonderful life" (see Malcolm 1984, 81). Similarly and along the same lines, one future self of Simone, Simone-c, might correctly judge that she is happier than her counterpart Simone-n while the other future self of Simone, Simone-n, might correctly judge that she is happier than her counterpart Simone-c; they can both be right because they refer to different standards of the good life. It is very plausible to assume that different possible future selves can differ in the standards of the good life (see also Sobel 1994, Bykvist 2010b, sec.2, as well as a hint to a similar point in Lambrozo 2013 who is responding to Paul 2015a).

What does all this imply for Simone's attempt to make a choice based on her expected future happiness? Again, she is asking a question "on behalf of" her future self (see above). Her current standards of happiness and of the good life are not relevant to her choice. We can assume that she knows (justifiably believes, etc.) that her standards will change, too, as a result of her choice. She is trying to make a decision that will make her happy in the future. She cannot defer to the (expected) judgments of her own possible future selves because these suggest different and

18 It is plausible to assume that there are also inadequate standards of the good.

19 We can leave the question open here whether the semantics of happiness attributions is contextualist or not (and rather invariantist or relativist; for a recent overview over some of the main semantic options in general see Stojanovic 2008), that is, whether or not the truth conditions or the meaning of sentences of the type "A is happy" or "A is happier than B" varies with attributor's context's standards of the good life. Could one deny that such statements have truth conditions in the first place? It seems very hard to deny that attributions of happiness are truth-apt; this assumption would certainly need a lot of argumentative support and motivation. It would also not allow for any question about comparative happiness. 
mutually incompatible choices, based on different standards of a good life. She has to make any judgment about happiness on the basis of someone's standards but there are no other standards of a present, future or possible self of hers available apart from the standards of Simone-c and Simone-n. There are no plausible meta-standards (or any reason to choose someone else's standards) that could help her. Also, it won't help to try to give preference to the standards of the modally "closer" possible future self (see above). Because of this variability of standards, there is no basis for making a comparative judgment about the degree of happiness of each of Simone's possible future selves (again, not denying that one can compare happy with unhappy future selves).

(e) Conclusion

All the above leads to the conclusion that in cases like Simone's it is impossible to compare the expected happiness of the two future possible selves. It is worth stressing here that this conclusion could be reached even on the basis of conceding - for the sake of the argument strong assumptions about measurability of individual states of happiness to the defenders of the unrestricted possibility of inter-world comparability (see the beginning of section 2.b).

Nothing changes if we consider happiness differences rather than happiness levels and ask questions like "How much happier than now would Simone be with (without) a child?". To be sure, one can compare a person who is definitely unhappy with a person who is definitely happy. But this won't help in cases like Simone's. And even if one figured out how to make sense of rough and imprecise comparisons of happiness levels this wouldn't help in cases like Simone's. 
In the case of inter-world comparisons of happiness we thus get to the same overall conclusion as in the case of inter-world comparisons of preference satisfaction above. In typical cases of big decisions like Simone's there is no basis for a rational choice - whether based on comparative happiness or on comparative satisfaction. In both cases the idea of the good of a person is inapplicable, leading to a collapse of the idea of a real choice. Are we forced to pick rather than choose then when it comes to some of the most important decisions in our lives ((see UllmannMargalit \& Morgenbesser 1977)?

\section{Conclusion}

Even if Simone knew everything there could be known, she could still not make the relevant comparison, and all that for lack of relevant matters of fact. It is worth contrasting this conclusion with recent work by Laurie Paul. She argues (see, e.g., Paul 2015a) that in the case of decisions like Simone's the subject cannot know in advance what it will be like to be in the relevant post-decisional future state (e.g., of being a mother for the first time). The subject has to be completely ignorant about the relevant phenomenal (qualitative) states. Therefore, Paul argues, traditional decision theory cannot deal with such cases in which future "what it's likes" are radically different from what the subject has had and known so far. Paul holds the preferences of the subject fixed through time and doesn't consider or compare different possible future selves with different preferences and utility functions. The latter, however, is essential to the problem discussed here. Apart from this, Paul's basic point is an epistemic one: there is something it is like to be in the relevant post-decisional state but one cannot know what it is like before the decision has been made. The problem discussed in this paper is rather differentmetaphysical rather than epistemic: there is no fact of the matter (known or unknown) about the 
comparative utilities of different possible future selves which would determine what is best for the subject. I work with the assumption that the subject has all the relevant knowledge and does not lack any relevant experience; Paul, in contrast, argues that her (very different) problem has to do with the lack of such knowledge and experience. ${ }^{20}$

Given all the above, there is no basis for a non-arbitrary and rational choice and thus, in a sense, no real choice. ${ }^{21}$ It does not help to argue that Simone could still chose an option that is not overridden by any alternative option even if she cannot choose an option that overrides all alternatives (see Raz 1985/86, 132-133; see also Hsieh 2007, sec.2): according to each possible future self a different option is non-overridden (similar problems arise for the satisficing proposal in Byron 2005).

The idea of a person's good simply does not seem to have application in cases like Simone's. This is puzzling and alarming because it concerns some of the most important ones amongst our decisions: some big life-changing decisions. How then should we make such decisions? Are there any normative guidelines? These questions are wide open (also see Williams 1981, 34-35 for brief hints at our problem). To be sure, the claim defended here is not that all or even most of

20 Our metaphysical problem is also different from semantic issues having to do with a potential semantic underdetermination of notions like "good", "better" or "best".

21 To be sure, I am not claiming that if agents like Simone choose one of the options they are doing something wrong or acting irrationally. - Chang 2015, sec.3 argues that when "given reasons" run out the will and the agent's commitment to one of the options can create reasons to stick with that option. I don't have to object to such a view because I am talking about rational choice in a more narrow sense of a choice based on given reasons. There is nothing wrong with extending our notion of reasons; however, our problem will still remain, no matter how one describes it (as a problem about reasons in general or one about given reasons in particular). - Sometimes there is no basis for a rational decision because the person simply lacks a relevant attitude. If I have never bothered with the qualitative differences between different brands of vinegar, then there is no basis for a rational choice by me between different brands of vinegar. Simone's situation is not like this: she does not have too few (0) but too many (2) attitudes to bring into the decision process (see on this also Harman 2009, 182, 189-190). 
our big decisions are like Simone's but rather that many are. We can also still compare pretty bad futures with pretty good futures but when it comes to attempts to compare futures in the same rough category (e.g., of "pretty good", as in Simone's case), then we are at a loss for the reasons explained above. And this is sufficient to create problems for standard views of rational choice (given interpretations of "utility" as preference satisfaction or as happiness). In contrast to authors like Bricker 1980 or Bykvist 2010a I thus propose to take a skeptical view concerning "Simonean" choices. ${ }^{22}$

It is very unclear what an alternative theory of rational choice - one that could also tell us something substantial about big decisions like Simone's - could look like. ${ }^{23}$ The Simonean choice situation is such that there are two options but neither is it true that one is better than the other, nor is it true that they are equally good. This is either a new type of case of incommensurability, or better: of incomparability of options (see Chang 1997 for an overview) or a case of indeterminacy (where it is neither true nor false that one option is better than the other, or that they are equally good). This, however, goes against the completeness axiom of classical rational choice theory (put in terms of betterness): for all options $\mathrm{x}$ and $\mathrm{y}$, either $\mathrm{x}$ is better than y, or y is better than x, or x and y are equally good (see, e.g., Luce \& Raiffa 1957, 23, $25)^{24}$

22 I don't deny that people make interpersonal as well as intrapersonal modal comparisons quite regularly. This is not the place to offer an interpretation of this practice or some error theory.

23 One might think that all this need not be a problem for rational choice theory if "preference" is interpreted as revealed preference (see also Andreou 2005 on this). However, it will obviously not help us here to say that Simone should go with the preferences that she will reveal after she makes her decision.

24 Things would get even worse if we added doubts concerning the equally basic assumption that rational preferences (betterness) are transitive (see xxx). 
One might object that neither indeterminacy nor incomparability nor their disjunction follows if two options do not stand in any of the three "classical" value relations better than, worse than or equally good as. Ruth Chang, for instance, has forcefully argued that there is a fourth positive value relation which she calls "parity" (and which others have called "rough equality") (see, e.g., Chang 2002). The failure of the three classical relations does not imply incomparability (or indeterminacy) because there is this fourth possibility. Applying this idea to our case, we could say that Simone's two possible futures (with a child, without a child) are on a par with respect to utility. Both her realistic future as a mother and her realistic future as a childless person are clearly better than a future as an inmate in a labor camp (see the remarks above about this kind of limited comparability of utility between the situations of different possible future selves). Even if Simone's two options are such that neither is one better than the other nor are they equally good, they are both still clearly comparable with other, third options. Hence, they cannot be incomparable (and their value can also not be indeterminate).

Without going too much into the details here, I would like to make the following brief remarks about this view. Certainly, if "parity" were just another name for "incomparable" or "indeterminate" or "incomparable or indeterminate", then nothing would have been gained at all. However, this is not what Chang and others have in mind. Also, if "parity" were just another name for coarse-grained equality (e.g., both of Simone's options belong into the category of "pretty good" options), then we would be back with the classical "trichotomy" view (according to which there are only the three classical value relations mentioned above) and parity wouldn't constitute a fourth positive value relation. That it is, requires some argument but we don't need to and should not go into this discussion here. Whether we are dealing with incomparability, 
indeterminacy or parity in cases like Simone's, the classical theory, the trichotomy view, fails.

This is already an important result. And Simone would thus not get an answer to her question

"What should I do?". If the two options were equally good then she might be justified in picking either one. But what if they're on a par? Or of incomparable or indeterminate value?

What then should we do with Simone's question "What should I do?"? Even if I am wrong and there exists, after all, an answer to the question what she ought to do, we are still pretty much in the dark about it. ${ }^{25}$ However, given the considerations presented here, I think we have good reason to think that there is no such answer. Some of the questions which we tend to consider to be of the greatest importance for us (like "What should I do with my life" and more specific variants of it) would thus turn out to be misguided and for this reason unanswerable. Whether being in this predicament is good or bad or something else, I leave to the reader to consider. ${ }^{26}$

25 In other words, this paper does not claim at all to have found an impossibility proof or some argument to the effect that rational choice is not possible in some or all cases of big decisions. Nothing nearly as strong has been argued for here. The point is rather that there is a serious problem for our orthodox conceptions of rational choice as applied to ideas of happiness or preference satisfaction, and that it is very unclear how one could respond to the problem.

26 One may also want to explore potential implications of the main conclusion here. Can, e.g., any sense be made of talk about the comparative value of different actual or possible lives (not to mention the idea of measuring such value in monetary terms)? Can we, for instance, say that a disabled person is worse or better or equally well than if she had not been disabled? (see on the latter issue also Barnes 2009). 


\section{References}

Adler, Matthew D. 2012, Well-Being and Fair Distribution: Beyond Cost-Benefit Analysis, Oxford: Oxford University Press.

Andreou, Chrisoula 2005, Incommensurable Alternatives and Rational Choice, Ratio 18, 249261.

Arrow, Kenneth J. 1963, Social Choice and Individual Values (2.ed.), New York etc.: Wiley.

Barnes, Elizabeth 2009, Disability, Minority, and Difference, Journal of Applied Philosophy 26, 337-355.

Bergström, Lars 1982, Interpersonal Utility Comparisons, Grazer Philosophische Studien 16/17, 283-312.

Binmore, Ken 2009, Interpersonal Comparison of Utility, in: Harold Kincaid \& Don Ross (eds.), The Oxford Handbook of Philosophy of Economics, Oxford: Oxford University Press, 540-559.

Bowie, G. Lee 1979, The Similarity Approach to Counterfactuals, Nô̂s 13, 477-498.

Bradley, Richard 2008, Comparing Evaluations, Proceedings of the Aristotelian Society 108, 85100.

Brandt, Richard B. 1979, A Theory of the Good and the Right, Oxford: Clarendon.

Bricker, Phillip 1989, Prudence, The Journal of Philosophy 77, 381-401

Briggs, Rachael 2015, Tranformative Experience and Interpersonal Utility Comparisons, Res Philosophica 92.2, 189-216.

Broome, John 1991, Utilitarian Metaphysics?, Jon Elster \& John E. Roemer (eds.), Interpersonal Comparisons of Well-Being, Cambridge: Cambridge University Press, 70-97. 
Bykvist, Krister 2010a, Can Unstable Preferences Provide a Stable Standard of Well-Being?, Economics and Philosophy 26, 1-16.

Bykvist, Krister 2010b, Happiness in a Flux? The Instability Problem, Journal of Happiness Studies 11, 553-565.

Byron, Michael 2005, Simon's Revenge: or, Incommensurability and Satisficing, Analysis 65, $311-315$

Chang, Ruth 1997, Introduction, Ruth Chang (ed.), Incommensurability, Incomparability and Practical Reason, Cambridge/MA: Harvard University Press, 1-34.

Chang, Ruth 2002, The Possibility of Parity, Ethics 112, 659-688.

Chang, Ruth 2015, Transformative Choices, Res Philosophica 92.2, 237-282.

Drakopoulos, Stavros A. 1989, The Historical Perspective of the Problem of Interpersonal Comparisons of Utility, Journal of Economic Studies 16 (4), 35-51.

Elster, Jon 1982, Sour Grapes - Utilitarianism and the Genesis of Wants, Amartya Sen \& Bernard Williams (eds.), Utilitarianism and beyond, Cambridge: Cambridge University Press, 219-238.

Elster, Jon \& Roemer, John 1991, Introduction, Jon Elster \& John E. Roemer (eds.), Interpersonal Comparisons of Well-Being, Cambridge: Cambridge University Press, 116.

Frankfurt, Harry G. 1971, Freedom of the Will and the Concept of a Person, The Journal of Philosophy 68, 5-20.

Gibbard, Allan 1986. Interpersonal comparisons: preference, good, and the intrinsic reward of a life, Jon Elster \& Aanund Hylland (eds.), Foundations of Social Choice Theory, Cambridge: Cambridge University Press, 165-193. 
Griffin, James 1986, Well-Being. Its Meaning, Measurement and Moral Importance, Oxford: Clarendon.

Hammond, Peter J. 1991, Interpersonal Comparisons of Utility: Why and How They are and Should Be Made, Jon Elster \& John E. Roemer (eds.), Interpersonal Comparisons of Well-Being, Cambridge: Cambridge University Press, 200-254.

Hare, Richard M. 1981, Moral Thinking. Its Levels, Methods, and Point, Oxford: Clarendon Press.

Harman, Elizabeth 2009, “I'll Be Glad I Did it” Reasoning and the Significance of Future Desires, Philosophical Perspectives 23, 177-199.

Harsanyi, John C. 1953-54, Welfare Economics of Variable Tastes, The Review of Economic Studies 21, 204-213.

Harsanyi, John C. 1955, Cardinal Welfare, Individualistic Ethics, and Interpersonal Comparisons of Utility, Journal of Political Economy 63, 309-321.

Harsanyi, John C. 1977a, Morality and the Theory of Rational Behavior, Social Research 44, 623-656.

Harsanyi, John C. 1977b, Rational Behavior and Bargaining Equilibrium in Games and Social Situations, Cambridge: Cambridge University Press.

Harsanyi, John C. 2008, Interpersonal Utility Comparison, Steven N. Durlauf \& Lawrence E. Blume (eds.), The New Palgrave Dictionary of Economics (2.ed), Basingstoke: Palgrave Macmillan, xxx.

Hausman, Daniel M. 1995, The Impossibility of Interpersonal Utility Comparisons, Mind 104, 473-490. 
Hennipman, Pieter 1995, Two Kinds of Interpersonal Utility Comparison, Donald Walker, Arnold Heertje and Hans van den Doel (eds.), Welfare Economics and the Theory of Economic Policy, Aldershot: Elgar, 157-180.

Hsieh, Nien-hê 2007, Is Incomparability a Problem for Anyone?, Economics and Philosophy 23, $65-80$

Hurka, Thomas 1993, Perfectionism, Oxford: Oxford University Press.

Jeffrey, Richard C. 1974, Remarks on Interpersonal Utility Theory, Sören Stenlund (ed.), Logical Theory and Semantic Analysis. Essays Dedicated to Stig Kanger on his Fiftieth Birthday, Dordrecht etc.: Reidel, 35-44

Kahneman, Daniel, Peter P. Wakker and Rakesh Sarin 1997, Back to Bentham? Explorations of Experienced Utility, The Quarterly Journal of Economics 112, 375-405.

Klocksiem, Justin 2008, The Problem of Interpersonal Comparisons of Pleasure and Pain, The Journal of Value Inquiry 42, 23-40.

Krasner, Daniel and Heller, Mark 1994, The Miracle of Counterfactuals: Counterexamples to Lewis's World Ordering, Philosophical Studies 76, 27-43.

Lambrozo, Tania 2013, Is it Rational to Have a Child? Can Psychology Tell Us?, Psychology Today, http://www.psychologytoday.com/blog/explananda/201303/is-it-rational-havechild-can-psychology-tell-us.

Little, Ian M.D. 2002, A Critique of Welfare Economics. A Retrospective Reissue, Oxford University Press.

Luce, R. Duncan \& Raiffa, Howard 1957, Games and Decisions. Introduction and Critical Survey, New York etc.: Wiley.

MacKay, Alfred F. 1975, Interpersonal Comparisons, The Journal of Philosophy 72, 535-549. 
MacKay, Alfred F. 1980, Arrow's Theorem: The Paradox of Social Choice. A Case Study in the Philosophy of Economics, New Haven \& London: Yale University Press.

Malcolm, Norman 1984, Ludwig Wittgenstein. A Memoir (2.ed.), Oxford: Oxford University Press.

Mill, John Stuart, Utilitarianism, Collected Works of John Stuart Mill (ed.: John M. Robson), Toronto: Toronto University Press 1963-1991, v.10, 203-259.

Morreau, Michael 2010, It Simply Does Not Add Up: Trouble with Overall Similarity, The Journal of Philosophy 107, 469-490.

Neurath, Otto 1973, The Problem of the Pleasure Maximum, Otto Neurath, Empiricism and Sociology (eds.: Marie Neurath and Robert S. Cohen), Dordrecht etc.: Reidel, 113-122.

Paul, Laurie A. 2015a, What You Can't Expect when You're Expecting, Res Philosophica 92.2, 149-170.

Paul, Laurie A. 2015b, Transformative Choice: Discussion and Replies, Res Philosophica 92.2, 473-545.

Ramsey, Frank Plumpton 1990, Truth and Probability, Frank Plumpton Ramsey, Philosophical Papers (ed.: David Hugh Mellor), Cambridge: Cambridge University Press, 52-94.

Raz, Joseph 1985/86, Value Incommensurability: Some Preliminaries, Proceedings of the Aristotelian Society 86, 117-134.

Robbins, Lionel 1938, Interpersonal Comparisons of Utility: A Comment, The Economic Journal $48,635-641$

Sartre, Jean-Paul 1970, L'existentialisme est un humanisme, Paris: Les éditions Nagel. 
Scanlon, Thomas M. 1993, The Moral Basis of Interpersonal Comparisons, Jon Elster \& John E. Roemer (eds.) 1991, Interpersonal Comparisons of Well-Being, Cambridge: Cambridge University Press, 17-44.

Schlick, Moritz 1939, Problems of Ethics (tr.: David Rynin), New York: Prentice-Hall.

Schoeffler, Sidney 1952, A note on modern welfare economics, American Economic Review 62, $880-887$.

Sen, Amartya K. 1970, Collective Choice and Social Welfare, Amsterdam etc.: Elsevier.

Sen, Amartya 1987, On Ethics and Economics, Oxford: Blackwell.

Sobel, David 1994, Full-Information Accounts of Well-Being, Ethics 104, 784-810.

Stojanovic, Isidora 2008, The Scope and the Subtleties of the Contextualism/ Literalism/

Relativism Debate, Language and Linguistics Compass 2.6, 1171-1188.

Ullmann-Margalit, Edna \& Morgenbesser, Sidney 1977, Picking and Choosing, Social Research 44, 757-785.

Ullmann-Margalit, Edna 2006, Big Decisions: Opting, Converting, Drifting, Royal Institute of Philosophy Supplement 58, 157-172.

von Neumann, John \& Morgenstern, Oskar 1953, Theory of Games and Economic Behavior, Princeton: Princeton University Press.

Wilburn, Ron 2010, Possible Words Without Doubt, Acta Analytica 25, 259-277.

Williams, Bernard 1981, Moral Luck, Bernard Williams, Moral Luck. Philosophical Papers 1973-1980, Cambridge: Cambridge University Press, 20-39.

Wolf, Susan 1997, Happiness and Meaning: Two Aspects of the Good Life, Social Philosophy and Policy 14, 207-225. 